\title{
JÓVENES UNIVERSITARIOS Y SOCIABILIDAD
}

\author{
PATRICIA WESTENDARP PALACIOS ${ }^{1}$ \\ LUIS GREGORIO IGLESIAS SAHAGÚN ${ }^{2}$
}

\begin{abstract}
RESUMEN
En este texto presentamos un trabajo de investigación realizado con jóvenes universitarios de la Universidad Autónoma de Querétaro (México), con el objetivo de conocer sus formas de sociabilidad. Preguntar por las formas de sociabilidad nos permite comprender los espacios, actividades y dinámicas desplegados por las/los jóvenes y el valor que dichas relaciones cobran en un contexto de desafiliación acelerada. Así, recuperamos el papel que juega la sociabilidad en términos de las posibilidades de relación y vínculo entre las juventudes y como espacio de encuentro y creación de sentidos.
\end{abstract}

\footnotetext{
${ }^{1}$ Profesora Investigadora de la Facultad de Psicología, Universidad Autónoma de Querétaro, México. Maestra en Psicología Comunitaria, Universidad de Chile. Líneas de trabajo: estudios socioculturales de las emociones, psicología comunitaria, juventudes, participación, acción comunitaria. Correo electrónico: patricia.westendarp@uaq.mx

${ }^{2}$ Profesor e Investigador de tiempo completo en la Facultad de Psicología, Área de Psicología Social, Maestría en Educación para la Ciudadanía, Maestría en Salud Mental de la Infancia y la Adolescencia, Universidad Autónoma de Querétaro, México. Psicólogo Social por la Universidad Autónoma Metropolitana-Xochimilco, México. Miembro asociado al grupo de investigación de psicología social de la Universidad de Oviedo. Associated fellow to Discourse Unit Manchester. Chercheur Invitée Institute d'Etudes Politiques, Sciences Po Lyon, France. Correo electrónico: greg@uaq.mx
} 
PALABRAS CLAVE: JUVENTUDES, PARTICIPACIÓN POLÍTICA, PRÁCTICAS DE

SOCIABILIDAD

\title{
JOVENS UNIVERSITÁRIOS E SOCIABILIDADE
}

\begin{abstract}
RESUMO
Neste texto apresentamos um trabalho de pesquisa realizado com jovens universitários da Universidad Autónoma de Querétaro (México) com o objetivo de conhecer suas formas de sociabilidade. Perguntar pelas formas de sociabilidade nos permite compreender os espaços, atividades e dinâmicas utilizadas pelos e pelas jovens e o valor que estes relacionamentos adquirem em um contexto de desfiliação acelerada. Assim, recuperamos o papel que tem a sociabilidade em termos das possibilidades de relacionamento e vínculo entre as juventudes e como espaço de encontro e criação de sentidos.
\end{abstract}

PALAVRAS-CHAVE: JUVENTUDES, PARTICIPAÇÃO POLÍTICA, PRÁTICAS DE

SOCIABILIDADE

YOUNG UNIVERSITY STUDENTS AND SOCIABILITY

\begin{abstract}
In this text, we present a research work carried out with young university students from Universidad Autónoma de Querétaro (México), aimed at gaining insight into their sociability means. Inquiring into sociability ways allow us to understand the spaces, activities and dynamics displayed by young male and female individuals and the value that these relationships have in a context of accelerated disaffiliation. Thus, we retrieve the role played by sociability in terms of relationship possibilities and the link between youths, as well as a gather place and creation of meanings.
\end{abstract}




\section{INTRODUCCIÓN}

El presente trabajo forma parte de una investigación más amplia de la Facultad de Psicología, titulada «Sociabilidad en jóvenes universitarios en Querétaro y repertorios interpretativos con los que dan sentido a la ciudadanía y la política», a cargo del Dr. Luis Gregorio Iglesias Sahagún, en la que colaboramos docentes, egresados y estudiantes de esta Facultad, en la Universidad Autónoma de Querétaro.

Así, en este texto recuperamos una de las fases de este proyecto, que fue el trabajo realizado en cuatro grupos de discusión para conocer la sociabilidad en las/los jóvenes universitarios. Dicha estrategia metodológica nos permitió acceder a los lugares comunes y de identificación colectiva de quienes formaron parte de esta conversación. Participaron estudiantes de las carreras de: Ciencias Naturales, Bellas Artes, Contaduría y Administración, Psicología, Ciencias Políticas, Ingeniería, Filosofía; representando la mitad de las facultades de la universidad. Como criterios de participación solicitamos que estuvieran en el tercer año de la carrera, para contar con un tiempo considerable de vida universitaria, y que fueran mayores de 22 años y menores de 29. El criterio de ser mayores a los 22 años responde al hecho de que pudieron participar (o no) en el proceso de elección presidencial de 2012, un proceso de participación política instituida.

De esta manera, los objetivos del artículo son: presentar una breve contextualización de las condiciones actuales de las juventudes en América Latina, así como los abordajes teóricos desde las cuales son estudiadas. Posteriormente, retomar la propuesta de la sociabilidad como una posibilidad de relación y vínculo entre las juventudes, así como un espacio de creación y encuentro de sentidos. Con ello, buscamos reconocer elementos de la política entendida como la forma de estar juntas/os-, que se juegan en estos encuentros y las posibilidades de los mismos para la construcción de vínculos sociales, ante 
el contexto de individualismo, indiferencia y violencia que vivimos en la última década en nuestro país.

\section{CONDICIÓN ACTUAL DE LAS Y LOS JÓVENES EN MÉXICO}

Como mencionamos anteriormente, en esta investigación trabajamos con jóvenes de 22-29 años, siendo el dato sociodemográfico uno de los criterios operativos para elegir esta población ${ }^{3}$. No obstante, reconocemos que dicha perspectiva sociodemográfica, como única categoría para definir a las juventudes, tiende a homogeneizar a las y los jóvenes (Alpízar y Bernal, 2003). Así, es necesario mencionar que adherimos a los aportes de la sociología juvenil propuestos por Duarte (2012), que comprende a lo juvenil y a las generaciones como relaciones sociales que se encuentran en permanente construcción. Siguiendo al mismo autor, lo juvenil hace referencia a las producciones culturales que las y los jóvenes despliegan o inhiben en su vida cotidiana (Duarte, 2000); mismas que serán distintas según los contextos y momentos históricos que se estudien.

De acuerdo con Rossana Reguillo (2012a), a mediados de la década pasada las juventudes en México viven un proceso de «desafiliación acelerada», donde existe un deslizamiento numeroso de jóvenes hacia ámbitos de la informalidad. En este sentido, habla de un creciente deterioro de las condiciones estructurales para incorporar digna y efectivamente a los jóvenes a la sociedad, de la falta de seguimiento por parte del Estado a las políticas sociales dirigidas a esta población y, también, del descrédito de las juventudes por la política formal. De esto último cabe resaltar que la Encuesta Nacional de Valores en la Juventud, realizada en 2012 por el Instituto Mexicano de la Juventud (IMJUVE, 2012), menciona que el $89,6 \%$ de las/los jóvenes no se interesan por la política y que existe una «extendida apatía» hacia esta. Lo anterior es considerado desde una visión

\footnotetext{
${ }^{3}$ De acuerdo con el Instituto Nacional de Estadística Geografía e Informática (2000), se considera población joven a la comprendida entre los 15 y los 29 años de edad.
} 
adultocentrista, — que retomaremos más adelante-, que no considera otras formas de hacer política que no sean la política partidista.

Así, Rivera (2013) menciona que en Latinoamérica la reestructuración de las políticas económicas ha contribuido a que las/los jóvenes tengan nuevos riesgos y tensiones, por lo que sus experiencias de vida son menos previsibles y más accidentadas. Siguiendo las ideas de Reguillo, Rivera menciona que «los actores juveniles se tienen que adaptar a la actual crisis/reestructuración de las instituciones que otorgaban certidumbre y estabilidad, ahora muchos de ellos saben que lo único que tienen seguro es que no hay nada seguro» (2013: 12). Por lo que miles de jóvenes han aprendido a sobrevivir en medio de carencias. Quienes logran tener acceso a la educación ya no tienen garantizada una movilidad socioeconómica. Y cuando las/los jóvenes logran acceder a un empleo, la mayoría lo hace en condiciones precarias. Respecto a la pregunta sobre ingresos mensuales que planteó la Encuesta Nacional de Valores en la Juventud (2012), el mayor porcentaje (46,7\%) respondió que ganan entre $\$ 1.821$ y $\$ 5.460$ pesos (96 USD y 287 USD, respectivamente). De acuerdo con el Instituto Nacional de Estadística y Geografía (INEGI) en 2016, el 41,35\% de jóvenes entre los 15 y 24 años que cuentan con un trabajo remunerado, no tiene acceso a la seguridad social.

No obstante, Rivera (2103) menciona que en estos contextos de exclusión/marginación, las juventudes crean un contrapeso a través de la inclusión/participación, donde desarrollan espacios de encuentro e interacción. Lo anterior, pocas veces es reconocido desde los mundos adultos debido a una mirada adultocéntrica. El adultocentrismo es definido por Duarte como una:

Categoría de análisis que designa un modo de organización social que sostiene relaciones de dominio entre aquello que es forjado como adultez, impuesto como referencia unilateral, respecto de aquello es que es concebido como juventud (también niñez y adultez mayor). (2016: 44) 
En este sentido, las/los jóvenes son relegados de las decisiones políticas, la producción de su trabajo les es enajenada, en los grupos familiares son relegados a posiciones de dependencia y en otros sistemas institucionales, les son impuestos saberes a través de la transmisión intergeneracional. Así, una mirada adultocéntrica, de tipo telescópica, diría Duarte, solo verá a las juventudes a través de la lente del mundo adulto. Por lo que desde esta mirada estática se generan discursos que son: homogeneizantes, estigmatizanes, invisibilizadores de las mujeres jóvenes y negadores de la subjetividad, de acuerdo con Alpízar y Bernal (2003). Por lo que será necesaria una mirada caleidoscópica, como lo sugiere Duarte (2000), para aproximarse a las juventudes desde la pluralidad y la heterogeneidad. Esto permitirá reconocer las diferencias que viven las/los jóvenes según sus condiciones de género, etnia, preferencia sexo-afectiva, momentos de vida, grupos sociales, posibilidades de participar en el mercado de producción y consumo, entre otras. En suma, una mirada que aluda a la construcción sociocultural del concepto de juventud.

Asimismo, una mirada caleidoscópica permite comprender las diversas formas en que las y los jóvenes se involucran en su entorno social y cultural más íntimo y en actividades creativas, donde construyen sentido a la realidad que les rodea y crean lazos de convivencia. En este punto, consideramos que el concepto de sociabilidad permite dar cuenta de las relaciones, interacciones y sentidos que las/los jóvenes dan al «estar juntos».

\section{LA SOCIABILIDAD}

A finales del siglo XIX, diversos autores denunciaban los cambios y efectos que la vida moderna suscitó sobre lo social. En este sentido, Simmel acusaba la sobrecarga de contenidos materiales y la exigencia de asuntos que esto conllevó; a su vez, señalaba la imposibilidad de entablar relaciones sociales que no estuviesen mediadas por el interés. Las consecuencias sociales de esta concepción racionalista de la vida fueron: la fragmentación social, el individualismo posesivo y la falta de solidaridad (Prestifilippo, 2016). Asimismo, 
Ferndinand Tönnies establecía la distinción entre las sociedades preindustriales y las sociedades industriales. Donde las primeras estarían caracterizadas por formas comunitarias de relación, basadas en el estar con los otros, como un fin en sí mismo, siendo afectivas y experienciales; y las segundas, las formas asociativas, serían predominantemente relaciones instrumentales en que el otro es un medio para obtener un fin. Estas formas dan lugar a una relación interesada, fría, contractual y racional entre las personas (Sánchez Vidal, 2007).

Así, encontramos similitudes en ambos autores al referir a las formas de relación donde el estar con otros es un fin en sí mismo. Al respecto, consideramos que el concepto de sociabilidad puede representar esta forma de estar con las/los otras/os. De acuerdo con Iglesias (2017), la temática de la sociabilidad ha sido posicionada desde los estudios sociales a partir de las humanidades, y más específicamente, desde la historiografía. Asimismo, retoma a González (en Iglesias, 2017), quien indica que la sociabilidad se ha convertido en una categoría de sentido común, donde pocas veces es contextualizada o explicitada.

Al respecto, en este escrito recuperamos la definición de Simmel sobre la sociabilidad, en palabras del autor «(...) designo la sociabilidad como la forma lúdica de sociación (...)» (Simmel, 1917/2002: 84). La sociabilidad no tiene finalidad material, ya que solo se persigue el estar satisfecho de ese momento. Así, la sociabilidad es la sociación en su estado más puro y se da entre iguales; siendo la forma más transparente y fácil de practicar de la interacción. De acuerdo con Prestiffilipo:

Puesto que aquello a lo que alude el concepto de sociabilidad es a una finalidad sin fin de la vida en común en la que los individuos ya no se relacionan a partir de objetivos que son trazados antes o por fuera del vínculo, sino que su único objetivo es el de entrar en relación con el otro. (2016: 319)

En este sentido, Iglesias y González (2018) mencionan que la sociabilidad «(...) alude a la forma que pueden adoptar las concurrencias, la forma del "estar 
haciendo algo juntos", las formas del "poner en común algo", las formas del "hacer en torno y a propósito de ese algo puesto en común"» (p. 121).

Por otra parte, Simmel recupera la dimensión estética de la sociabilidad, ya que la sociabilidad, al igual que el arte, es una forma sublimada de las fuerzas de la realidad, desvaneciendo su peso y convirtiéndose en el algo atractivo. Al respecto, Fernández (1999) plantea que en la vida cotidiana, las personas presentan un alto grado de eficiencia y utilidad, pero también, las personas buscan producir formas donde la realidad no solo sea funcional e instrumental, sino también bella. Al recuperar la estética de la sociabilidad, recuperamos también los afectos que forman parte de este encuentro, del estar con los otros. Entendiendo los afectos como la parte sustancial de los motivos, valores, significados, aspiraciones y desilusiones de las colectividades (Fernández, 2006).

Por otra parte, Díaz, Grassi y Mainini (2011) sostienen que el concepto de sociabilidad planteado por Simmel se encuentra vacío de contenido político y social, ya que no apunta a la movilidad o reconstrucción de la sociedad. En cambio, estos autores utilizan el concepto de socialidad propuesto por Jesús Martín Barbero, quien recupera los elementos de Simmel, pero también menciona que el estar juntos tiene una finalidad que es horadar el poder.

Contrario a lo que dicen estos autores, Prestifilippo (2016) señala que la sociabilidad tiene un carácter democrático, ya que esta pone en suspenso las determinaciones materiales, específicamente las diferencias de clase y de estatus, de ahí que hable de la dimensión ético-política del concepto. Sin embargo, esto no significa que la sociabilidad vaya a resolver las desigualdades sociales en las sociedades capitalistas.

La sociabilidad no resuelve las desigualdades sociales que dividen a la sociedad en clases, así como tampoco disuelve la estructura injusta de distribución de estatus. La sociabilidad es el juego en el que «se hace como sí» todos fueran iguales y al mismo tiempo como se hiciera honor a cada uno en particular. (Prestifilippo, 2016: 319) 
La sociabilidad, al igual que las formas artísticas, no puede ser identificada con la realidad, pero sí habla de ella, es una escenificación del ideal de sociedad que los individuos y grupos aspiran en sus interacciones. «La sociabilidad apunta a los anhelos sociales de reconciliación» (Prestifilippo, 2016: 320). En esto reside la dimensión ético-política del concepto. Así, el estar juntos propuesto por la sociabilidad nos recuerda la definición que Hannah Arendt plantea sobre la política: «La política trata del estar juntos y los unos con los otros de los diversos» (Arendt, 1993: 45). Por tanto, en este texto, sostenemos el uso de este concepto y reconocemos la dimensión ético-política que tiene y la potencialidad para pensar las relaciones sociales y los vínculos entre las personas.

Por el contrario, si el concepto de sociabilidad es entendido como un modelo normativo, artificial y por lo tanto, no generalizable, entonces, este concepto nos permite cuestionar las unilateralidades en las que puede recaer el pensamiento político contemporáneo. Pero entonces la sociabilidad no funcionaría como una llave que permita superar el conflicto trágico entre igualdad y libertad, sino que permitiría volver a él nuevamente. (Prestifilippo, 2016: 321)

\section{ANÁLisis de RESUltados}

En los grupos de discusión realizados, observamos que existe una interdependencia entre los espacios, los temas de conversación y las personas con las que conviven las/ los jóvenes universitarios. De esta manera, los gustos, intereses e inquietudes que tengan, les motivan a asistir a ciertos lugares y a establecer vínculos con ciertas personas. A su vez, los escenarios donde las juventudes despliegan su vida cotidiana posibilitan el encuentro con determinadas personas, así como tratar ciertos temas de conversación $\mathrm{y}$, por último, según las personas con las que conviven y la afinidad que se tenga con 
ellas, determinará los espacios a los cuales asisten, así como los contenidos de las pláticas entre las y los jóvenes.

De igual forma, la edad, el ser más o menos joven, influye en los espacios y las prácticas de la sociabilidad. Ya que a las/los jóvenes de menor edad se les «permite socialmente» emborracharse, tener actitudes irresponsables, «fiestear» sin control; todos estos discursos estereotipados que ya no son permitidos para quienes están más cerca de abandonar la categoría de joven.

De esta manera, proponemos tres categorías para analizar la información producida en los grupos de discusión respecto a la sociabilidad en jóvenes universitarios: los lugares o espacios para sociabilizar, las formas de sociabilidad y la participación política. Si bien estos elementos se encuentran relacionados entre sí, para fines expositivos realizamos esta diferenciación.

\subsection{ESPACIOS PARA LA SOCIABILIDAD}

Los espacios de sociabilidad que fueron mayormente mencionados son: las fiestas, los antros (discotecas), los bares, salir a comer, invitar amigos a las casas, esto último fue referido principalmente por estudiantes que son foráneos. En menor medida, mencionaron lugares como el cine o el teatro. Lo que nos indica también que son espacios que representan, en su mayoría, un costo significativo para las/los estudiantes. De igual forma, comentan que participar en actividades deportivas o artísticas, y en organizaciones de la sociedad civil posibilita la sociabilidad entre jóvenes. La escuela y el trabajo, en el caso de las/los jóvenes que además de estudiar, trabajan, son espacios también de sociabilidad. Si bien ambos contienen una forma asociativa de relacionarse, por los vínculos instrumentales que existen en estos espacios; también son desplegadas formas 
comunitarias de relacionarse, dando lugar a la sociabilidad y en el caso que mencionamos aquí, permite vínculos de amistad.

(...) también te topas con gente en los pasillos y ahí a veces se abre un poco más el espacio a otras cuestiones, pero dentro de ese mismo espacio académico también pasan otras cosas muy fuertes, donde la sociabilidad pasa como a un término mucho más personal, que es cuando empiezas a compartirle cosas que no es solo del ámbito académico, sino es cómo te sientes, tu vida, tu historia, cómo entiendes algunas cosas y empiezas a hacer amigos, tú no sabías que iban a estar ahí, pero se encontraban en ese momento y, pues, se generan lazos muy fuertes de amistad. (Estudiante hombre)

Llama la atención cómo en el ámbito de la escuela se considera que hay una forma más libre de asociación entre las y los jóvenes que en el trabajo. Dice una estudiante:

Sí, pues, también yo creo que, luego estás en la escuela y dices «ay, ¿qué hacemos?, vamos a tal lado», se van al bar o se van a la casa de alguien y en el trabajo es como «ay, ¿qué quieres hacer?, ay, pues, irme a dormir, ¿no?», o sea, aparte lo planeas con más tiempo, o sea, en la escuela como que siempre es espontáneo, «¿qué hacemos?, ah, pues, a casa de fulanito». Y en el trabajo es, «¿y qué tal si dentro de quince días salimos?». (Estudiante mujer)

De esto último, el ritmo acelerado de la vida hace más difíciles los encuentros espontáneos entre las/los jóvenes; destino que se muestra de manera más evidente a quienes se avecinan a la adultez. Lo que implicaría ya no pertenecer a este espacio más espontáneo representado en la vida universitaria, para dedicarse de lleno a la actividad laboral. Lo anterior también es reforzado por las nociones tradicionales adultocéntricas en las sociedades capitalistas, que a decir de Duarte (2013), conciben el ser adulto —o quien está cada vez más 
cerca de serlo- - como un ser rígido, aburrido, establecido y con la sensación de haber llegado a un punto terminal.

\subsection{LAS REDES SOCIALES COMO ESPACIO PARA LA SOCIABILIDAD}

En los cuatro grupos de discusión, el tema de la sociabilidad a través de las redes sociales surgió de manera recurrente y espontánea, tanto que en uno de estos grupos, aunque se quisiera cambiar de tópico, volvían a hablar de las redes sociales. Así, consideramos a las redes sociales como un espacio donde son desplegadas interacciones y relaciones entre las/los jóvenes a través de los distintos dispositivos electrónicos, así como de sus aplicaciones.

Resalta también que pocos reconocieron pasar mucho tiempo en las redes sociales, como si el hecho de reconocer esto fuera algo negativo. Asimismo, señalan que cuando eran más jóvenes pasaban más tiempo haciendo uso de estas, lo cual es considerado como algo común en los jóvenes de menor edad. Comentan que la mayor parte del tiempo que destinan actualmente al uso de las redes sociales es para la escuela, para hacer trabajos y compartir información académica. Las redes que más utilizan son Facebook, Twitter y Whatsapp. Y respecto a Tinder, que es una aplicación para conocer personas, todos la mencionaron, pero refiriendo a que un amigo o una amiga les contaron cosas respecto de esta aplicación; ninguno dijo haberla utilizado. Sobre esta última aplicación, resalta el hecho de que nadie reconociera directamente su uso, e incluso que se viera por algunas/os jóvenes como algo vergonzoso. Por lo que resulta interesante indagar más sobre el coqueteo y la vivencia de la sexualidad a través de estas redes sociales, aspectos que también forman parte de la sociabilidad.

Rossana Reguillo (2012b) menciona que las «tecnologías de proximidad» que sostienen las redes sociales generan dos efectos en las y los jóvenes: los convierten en autores y propician el uso activo de dispositivos y contenidos. A su vez, la autora menciona la carencia de instrumentos y la dificultad para realizar una cartografía de estas nuevas gramáticas en la producción de sentido; no 
obstante, es importante comprender, sin emitir juicios valorativos, las nuevas configuraciones en la interacción que las redes sociales permiten.

De esta manera, encontramos que los discursos de las/los jóvenes sobre las redes sociales como espacio de sociabilidad se encuentran atravesados por diversas tensiones que podríamos resumir como posibilidades y dificultades en torno a distintos elementos que enunciamos a continuación.

a) Cercanía vs. distancia. La cercanía permite poner en contacto a personas que se encuentran lejos geográficamente, y la distancia representa la imposibilidad de tener un conocimiento «completo» de las personas. Aunque existen los «emoticones» en distintas aplicaciones, hay una mayor valoración por las interacciones cara a cara.

(...) quizás podrías conocer a alguien por internet «ah, no que no sé qué, tienes la misma locura que yo», «ah, pues, vamos a conocernos, ¿no?», un negocio o cualquier otra cosa, pero yo creo que la relación se define ya cuando lo ves a los ojos y ves cómo se comporta y se ríe, cómo habla, lo que dice y lo que no dice. (Estudiante hombre)

b) Posibilidad de conocer gente nueva vs. el riesgo y la desconfianza de conocer gente nueva. Todas/os comentaron que agregan a sus redes solo a personas que conocen o con las que tienen amigos en común.

c) Semejanza vs. diferencia. Comentaron que el uso de las redes es un filtro que te permite acercarte a personas con gustos afines a ti, no obstante, lo anterior limita también acercarte a personas que son diferentes a ti, que no tienen tus mismas etiquetas.

Pero este, no sé, o sea, en ese caso pues está padre, las redes sociales como que sí te pueden ayudar un poco para hacer como un filtro, ¿no?, igual con una persona así que estás en el Facebook que pone cosas que no estás de acuerdo, o 
que te molesta, o puedes ver qué tipo de música le gusta, que para mí es muy importante, este, pues ya luego, luego, sabes por dónde sí, por dónde no. (Estudiante hombre)

d) La relación con el tiempo y la comunicación. La inmediatez en las comunicaciones es valorada positivamente cuando tienes poco tiempo para comunicarte con otras personas. Por otra parte, mencionaron sentirse obligadas/os a estar conectadas/os todo el tiempo y a responder inmediatamente. Refieren a una saturación de comunicaciones; aunque algunos mencionaron que hay funciones en las aplicaciones que permiten no aparecer como disponible todo el tiempo, como vemos en la segunda cita que presentamos a continuación:

A mí una cosa que me molesta mucho en las redes sociales es la manera en cómo te relacionas hoy en día es que siempre tienes que estar disponible, o sea, nunca ya no tienes ningún momento en que tú digas: «no estoy disponible, no me llames a esta hora, no quiero recibir un maldito mensaje tuyo.» (...) nunca puedes decir no, porque: «qué mala onda, no me contestaste». (Estudiante mujer)

(...) de las mismas aplicaciones, tú puedes restringir el contenido que estés viendo, entonces. Por ejemplo, no quieres que vean que dejaste en visto, puedes desactivar eso, si tú no quieres saber que una persona está publicando cosas, tú la puedes quitar sus publicaciones y borrar datos. O sea, creo que tú puedes en las redes sociales, tú sí puedes restringir qué quieres y lo que no quieres, como en la vida, ¿no? (Estudiante hombre)

e) Pertenecer vs. no pertenecer. Las redes sociales permiten la posibilidad de pertenecer a ciertos grupos y, a la vez, el riesgo de no pertenecer. Como dice una estudiante: «si no tienes alguna red social, es como si no existieras (...)». $\mathrm{Al}$ respecto, otra estudiante comenta: 
O la sociedad te lo exige, ¿no? Por ejemplo, el otro día Javi puso: «uuuu» y yo no entendí el «uuu». (Se ríen), «¿Por qué uuu?». Y no me dio risa, pero ahora ya sé de qué trata el chiste cuando la gente dice: «uuu». O sea, como que te obliga porque, si no, no entras en la conversación. «¿Qué es eso?». Hasta que entendí el chiste pude participar y de ahí como sacar o seguir interactuando en un nivel más relajado con determinadas personas. (Estudiante mujer)

f) Lo público vs. lo privado. Aunque en ciertas aplicaciones hay formas de publicar contenidos a todos tus contactos (el muro de Facebook, por ejemplo) y otras solo de manera personal (mensajes por inbox en Facebook), refieren a las tensiones que existen entre los límites de establecer qué es lo público y qué es lo privado.

Bueno, yo también lo veo como esta cuestión de que ahora qué es público y qué es privado, ahora se supone, bueno yo veo una saturación de información por todos lados, todo el tiempo, de imagen, de todo, o sea de vidas, de secretos, todo está ahí, es como para muchos un diario personal que también es como un portal donde sabes que alguien te lee, que alguien te está viendo, que sí eres como importante de cierta manera. (Estudiante mujer)

g) Activar la participación política vs. desactivar la participación política. De esto último, mencionan que las redes permiten hacer denuncias y compartir información respecto a temas políticos relevantes, no obstante desacreditan a los «activistas de pantalla» que no llevan a la práctica lo que publican en sus muros, refieren a esto como algo cínico.

\subsection{HACER CLICK: FORMAS DE SOCIALIZACIÓN}

Las/los universitarios mencionan que la sociabilidad se da principalmente por los intereses que tienen en común con otras/os jóvenes, esto refiere a «hacer click». 
(...) pues todo depende de la experiencia no, de la apertura que tengas con la gente y, pues, quién sabe qué será y es realidad, pero es un click que haces con la persona, y si haces ese click, le tienes confianza, este, puede haber amigos hasta por internet, ¿no?, o sea, porque, así salen de repente y a veces (...) más bien tiene que ser, así de cara a cara. (Estudiante mujer)

Esta metáfora del click alude a cuando dos piezas embonan y quedan enlazadas, y podemos decir que está hecho de componentes afectivos, como estas motivaciones que te mueven a estar con el otro. La sociabilidad se da también a través de cómo nos mostramos a los otros: «hacerse atractivo»: ser cordial, ser empática/o «tratas de ser como cordial, simpático, ¿no? Para no ser como tan nefasto» (Estudiante mujer). Así, recuperamos lo que dice Simmel respecto a «las cualidades personales de la amabilidad, cultura, cordialidad y capacidades de atracción de todo tipo deciden sobre el carácter del estar juntos puramente sociable» (Simmel, 1917/2002: 84).

Otro elemento que mencionaron como formas de sociabilidad fue el alcohol, visto como un «lubricante social», como una bebida social que invita al encuentro. Así, las/los jóvenes señalaron, en su mayoría, reunirse a beber en casas, ya que es más barato. Dice un joven estudiante: «La manera en que vas a encontrar a tu grupo, con el que vas a estar casi toda la carrera, es una peda. O sea, los identificas y dices: "Ah, con estos voy, con estos güeyes, con estos voy a estar"». Esto aparece como algo tan común que quien no bebe alcohol es considerado/a como antisocial, como lo señala una estudiante que no bebe.

La conversación también es una forma de sociabilidad, como lo refiere Simmel (1917/2002), es la forma del intercambio del hablar donde la materia ya no es más que el soporte imprescindible para dicho intercambio, el hablar se convierte en un fin en sí mismo. Esto no significa que los contenidos de las conversaciones tengan que ser indiferentes, el autor menciona que deben ser interesantes e incluso importantes; siempre y cuando dicho contenido no constituya la finalidad en sí misma. En el caso de esta investigación, como 
mencionamos anteriormente, según las personas y el ambiente serán los temas sobre los cuales conversan las/los jóvenes.

Yo creo que depende, ¿no?, porque también como dentro de todos tus amigos como que los separas, ¿no? «Ay, estos son mis amigos de la carrera, estos son los de toda la vida, estos son los de la peda'», je, o cosas así, ¿no? Entonces, dependiendo, pues, será el tema de conversación, ¿no? Con los de la carrera igual y hablas más cosas en torno a eso, ¿no?, lo que estás estudiando y ajá, cosas así, y los de toda la vida, pues igual y tus problemas personales, o cosas así, yo creo. (Estudiante mujer)

Así, los temas de conversación más comunes que mencionaron son: experiencias y viajes, y para aquellos que son foráneos, sobre sus lugares de origen. Nuevamente aparecen las redes sociales, es decir, lo que circula en las redes es tema de conversación, ya sea cuando algo se hace moda y se considera como gracioso, o temas de denuncia. En menor medida mencionaron que platican de temas de política, y cuando estos surgen, es cuando hay confianza con las personas que hablan, primero tratan temas superficiales y después otros de política. Respecto a estos temas «superficiales», retomamos lo que Simmel sostiene:

De este contexto general se desprende que también el contar historias, chistes, anécdotas, aunque muchas veces puede ser un relleno y una muestra de pobreza de recursos, a menudo puede mostrar un tacto sutil en el que se entonan todos los motivos de la sociabilidad. (...) El hecho de que se lo dice y escucha no es un fin en sí mismo, sino un puro medio para la vivacidad, para la comprensión mutua, para la consciencia de comunidad del círculo. Se da así no sólo un contenido en el que todos pueden participar por igual, sino además es el don de un individuo a todo el conjunto, pero éste hace que el donante, por así decir, se vuelva invisible detrás de aquél: la historia realmente perfecta se mantiene en el feliz punto de equilibrio de la ética de la sociabilidad, en la que tanto lo 
individual subjetivo como el contenido objetivo se han disuelto del todo para servir a la pura forma de la sociabilidad. (1917/2002: 96)

Así, temas relacionados con la política aparecen como algo de lo que se habla s se da, y si surge espontáneamente. Una estudiante menciona que deberíamos estar «obligados» a hablar de política. Nos preguntamos: ¿obligados por quién y además de qué política? Tal vez por esto aparece en menor medida este tema de conversación, ya que al concebir la política como una obligación, hace que se pierda el encanto de hablar de esta misma. Cabe mencionar que en la Encuesta Nacional de Valores en la Juventud (2012), «la obligación» es la respuesta que tiene el porcentaje más alto de razones por las cuales las/los jóvenes participarían en la política. Esto nos hace preguntarnos por la necesidad de reencantar la política, sacarla del plano de la obligación.

\subsection{PARTICIPACIÓN POLÍTICA}

Sobre la participación política, las/los jóvenes mencionaron que en Querétaro hay distintos espacios para trabajar estos temas, como son lugares de simpatizantes y adherentes al movimiento del Ejército Zapatista de Liberación Nacional, talleres de performance, además de lugares de encuentro de obreros y artesanos. Estos son espacios donde participan jóvenes y adultos. Igualmente comentan que hay carreras que se interesan más por estos temas y usualmente son las que pertenecen al campo de las ciencias sociales y las humanidades.

Otro tema recurrente fue el individualismo, que impide que los demás se preocupen por los otros. Como lo menciona Rivera (2013), hoy en día,

(...) hacer frente a la experiencia de la exclusión ha sido dejado en manos de cada una de las personas, para ello estas deben de valerse de sus propios recursos y habilidades. (...) esta situación coloca a las personas en una lógica de una eterna competencia, creándose la percepción de que cualquier asomo de solidaridad familiar o comunitaria resulta contraproducente o irrelevante. (Rivera, 2013: 15) 
Cuando refieren a temas de política, son los sentimientos de disconformidad y hartazgo los que enmarcan sus discursos. A decir de Moore (1989), sin los fuertes sentimientos morales de indignación, los seres humanos no actuarían en contra del orden social. En este sentido, es disconformidad y hartazgo hacia las políticas y reformas del actual presidente del país Enrique Peña Nieto (20122018), y hartazgo de que sigan sucediendo situaciones de violencia e impunidad, como la desaparición forzada de los 43 estudiantes de Ayotzinapa ${ }^{4}$.

Creo que también es como por empatía, ¿no?, en general, pues también en mi círculo como que sí hablamos de ese tipo de cosas. Y más que nada que, o sea, más que ser como revolucionarios o algo así, es porque somos humanos y porque es algo importante que igual y no te pasa a ti, pero dices, o sea, «qué mala onda que estén pasando esas cosas». (Estudiante mujer)

También existe otra emoción que se cuela en el discurso de la participación política y es el miedo.

Y también tengo una amiga que sí es como muy luchona, ¿no?, y como que está muy al tanto y sí va a marchas y a meetings, pero pues también a mí me da un poco de miedo por ella, ¿no?, porque así como están las cosas, pues quién sabe si a ella le pueda pasar algo, ¿no? (Estudiante mujer)

Casos como la desaparición de los normalistas de Ayotzinapa indignan y movilizan pero también paralizan, dan miedo. Como lo menciona Cavarero (2003), el miedo es una emoción que paraliza, pero que permite aún a las

\footnotetext{
${ }^{4}$ Refiere a los hechos ocurridos el 26 de septiembre de 2014, cuando distintos sectores de las fuerzas públicas participaron en la desaparición forzada de 43 estudiantes de la Escuela Normal Rural Raúl Isidro Burgos, de la localidad de Ayotzinapa, en el municipio de Tixtla, estado de Guerrero.
} 
personas movilizarse para ponerse a salvo. No obstante, a la par del miedo hablan de una empatía que intenta sentir lo que el otro siente.

(...) yo sí siento como esa preocupación, aunque a mí no me ha pasado, que no me han quitado mi casa, que no han matado a nadie de mi familia, yo sí siento como esa inquietud de saber, o sea, de preguntar «oye, ¿tú qué crees que podamos hacer?». (Estudiante mujer)

Tal vez la empatía de un interés común que mueve a encontrarse con otros pueda ser un móvil que permita también dolernos con otros. Contra el atomismo social del liberalismo económico, Simmel proponía un colectivismo producto de formas ancladas en la solidaridad: en el amor y la empatía (Prestiffilipo, 2016). A través del sentido del tacto desplegado en la sociabilidad, Simmel (1917/2002) sostiene que este es una autorregulación que pone límites a las impulsividades individuales y a la acentuación del yo.

Por último, también aparece la idea de la organización desde las cosas pequeñas, desde las propias trincheras, como: trabajar con niños, cuidar el medioambiente, tener prácticas responsables de consumo. Así, como sostiene Rivera (2013), parece que las/los jóvenes se vuelcan sobre sus mundos y estilos de vida «(...) de una forma más cotidiana y menos épica. En este sentido resultan ser los creadores-generadores de nuevas sensibilidades y de nuevas identidades»» (p. 21). Es decir, generan propuestas novedosas en el nuevo mapa de la cohesión social.

\section{CONCLUSIONES}

Indagar en las formas de sociabilidad entre las/los jóvenes y sus vínculos con la participación política es un tema relevante en nuestro país, considerando la desafiliación institucional acelerada que viven las juventudes, así como las condiciones de violencia que se vislumbran en México a partir de finales de 2006, con la «guerra contra el narcotráfico», emprendida por el presidente en turno 
Felipe Calderón Hinojosa (2006-2012). Si bien en este texto el objetivo no es hablar de las consecuencias sociales de esta guerra, es importante referir que las/los jóvenes son quienes más han sufrido dichas consecuencias: asesinatos, desapariciones forzadas, levantones para realizar trabajos forzados, entre otras. La magnitud de estos hechos ha llevado a distintos autores a hablar de juvenicidios (Valenzuela, 2015). En México, a nuestras/os jóvenes los están matando.

Así, en este contexto resulta imprescindible estudiar, a través de diversos frentes y temáticas, elementos que permitan tejer lazos entre las/los jóvenes, recuperar elementos que permiten dar forma al «estar juntos». En un contexto social con vínculos tan debilitados, estos temas pueden aportar pistas para reconstruir el tejido social. Asimismo, es crucial indagar estos temas desde sus propias perspectivas. En este sentido, como investigadores de mayor edad, y desde la academia, debemos hacernos cargo de nuestras implicaciones y evitar una mirada adultocéntrica que impida ver la pluralidad de experiencias de las juventudes.

De esta manera, según los resultados producidos en esta investigación, sugerimos algunos elementos para seguir profundizando en el tema. En primer lugar, desde una mirada caleidoscópica (Duarte, 2000), es importante recuperar la pluralidad de las/los universitarias/os, distinguiendo las experiencias de las mujeres y varones jóvenes, de quienes trabajan, quienes solo estudian, quienes son foráneos y han llegado a Querétaro a estudiar; entre otras condiciones. Asimismo, al realizar la investigación en una institución pública de educación superior, resulta interesante considerar la relación que existe entre la universidad pública, el papel del conocimiento y las diferencias entre las áreas de estudio, con las prácticas de sociabilidad y la participación política de las/los jóvenes. Estos son temas que no fueron centrales al inicio de la investigación, pero se sugiere que son relevantes para seguir indagando.

Igualmente, es necesario continuar estudiando la potencialidad de las prácticas de sociabilidad que despliegan las juventudes. Generar espacios de 
encuentro intergeneracionales, de cooperancia intergeneracional —como los llama Duarte (2013) —, que permitan comprender a las/los jóvenes desde distintos lugares. Así, en las posibilidades de reconstruir tejido social, podremos recuperar los aportes que las/los jóvenes realizan, no como la llave del futuro, sino como otro actor social más dentro de la sociedad.

Por otra parte, de estos mismos resultados recuperamos la importancia de la escuela y el trabajo como espacios institucionales que permiten la asociación y sociabilidad de las juventudes. Lo anterior implica un reto importante, ya que si hablamos de que existe una continua y creciente desafiliación de las/los jóvenes en estas instituciones, resulta imperante demandar la mejora de condiciones educativas y laborales de las juventudes, así como asegurar que más jóvenes puedan ingresar en estos espacios.

Otro elemento importante de considerar es el papel de las redes sociales en las juventudes. Si bien, distintos estudios hablan de las posibilidades y de las implicaciones que han tenido las redes sociales en las interacciones sociales (Reguillo, 2012b, Iglesias y González, 2018), es necesario recuperar las voces de las/los jóvenes respecto al uso que dan a las mismas. También, debemos realizar este acercamiento de manera situada, sabiendo que en determinados momentos y escenarios, las juventudes pueden asignar sentidos y significados distintos al uso de estas. Además de las tensiones que generan las redes sociales en los discursos presentados por las/los jóvenes universitarios en esta investigación, retomamos lo que mencionan Iglesias y Carbajal (2018) al respecto, las redes sociales aparecen en este caso como orientadoras de temas de conversación pública, así como una posible extensión de la plaza pública; esto aludiendo a la posibilidad de catalizar procesos comunicativos y colectivos.

Asimismo, dentro de las prácticas de sociabilidad, encontramos que la conversación y la afectividad son elementos centrales para generar vínculos con las/los otros/as. De esta forma, consideramos relevante seguir indagando por el potencial político de la amistad, donde los fines instrumentales de las relaciones pasan a otro término, y lo principal es el estar con las/los otros. Como lo 
mencionamos anteriormente, esto resulta crucial en nuestro contexto actual, donde el miedo, el individualismo y la desconfianza se han convertido en una forma de relación común en las interacciones sociales.

RECIBIDO: 3 DE SEPTIEMBRE DE 2018

ACEPTADO: 5 DE ABRIL DE 2019

\section{BiBLIOGRAFÍA}

AlPíZAR, L. y BERNAL, M. (2003). La construcción social de las juventudes. Última Década, 11(19), 105-123.

ArendT, H. (1993). ¿Qué es la política? Barcelona: Paidós.

Cavarero, A. (2003). Horrorismo. Nombrando la violencia contemporánea. México, DF: Antrhropos Editorial/Universidad Autónoma Metropolitana.

DíAZ, N., GRASSI, L. y MAININI, C. (2011). Socialidad: los modos de apropiación del espacio público. Questión, 1(9), 1-12.

DuARTE, K. (2000). ¿Juventud o juventudes? Acerca de cómo mirar y remirar a las juventudes de nuestro continente. Última Década, 8(13), 59-77.

. (2012). Sociedades adultocéntricas: sobre sus orígenes y reproducción. Última Década, 20(36), 99-125.

. (2013). Acción comunitaria con jóvenes. Desafios generacionales. Última Década, 21(39), 169-195.

(2016). Genealogía del adultocentrismo. La constitución de un patriarcado adultocéntrico. En K. DuARTE y C. Álvarez (Eds.), Juventudes en Chile. Miradas de jóvenes que investigan (pp. 17-47). Santiago, Chile: Facultad de Ciencias Sociales, Universidad de Chile.

FERnÁnDEZ, P. (1999). La afectividad colectiva. México DF: Alfaguara.

. (2006). El concepto de psicología colectiva. México, DF: Universidad Nacional Autónoma de México.

IGLESIAS, L. G. (2017). La sociabilidad, una puesta al día. Revista Digital@UAQRO, $10(2), 62-76$. 
IgLESIAS, L. G. y GonZÁLEZ, R. (2018). Tecnologías emergentes, redes al acecho de la sociabilidad. Teknocultura, 15(1), 119-137.

Iglesias, L. G. y CARbajal, J. (2018). Proyecto de investigación «Sociabilidad en jóvenes universitarios en Querétaro y repertorios interpretativos con los que dan sentido a la ciudadanía y la política», a cargo del Dr. Luis Gregorio Iglesias Sahagún. Facultad de Psicología. Universidad Autónoma de Querétaro. Septiembre 2016-Agosto 2018. (Manuscrito no publicado).

Instituto MexicAno De LA Juventud (IMJUVE). (2012). Encuesta Nacional de Valores en la Juventud. Recuperado de: https://www.imjuventud.gob.mx/imgs/uploads/ENVAJ_2012.pdf

INEGI. (2000). Los jóvenes en México. México, DF: INEGI. (2016). Panorámica de la población joven por condición de actividad.

Recuperado de: http://www3.inegi.org.mx/sistemas/tabuladosbasicos/tabniveles.aspx?c=33655 $\& s=e s t$

MoOre, B. (1989). La injusticia: bases sociales de la obediencia y la rebelión. México, DF: Universidad Nacional Autónoma de México.

PrestifiliPPO, A. (2016). Libertad, igualdad, sociabilidad. Tensiones ético-políticas en la sociología de Georg Simmel. En E. VerniL y H. BorisOnIK, Georg Simmel, un siglo después: actualidad y perspectiva (315-322). Buenos Aires: Universidad Autónoma de Buenos Aires.

Reguillo, R. (2012a). De las violencias: caligrafía y gramática del horror. Desacatos, 40, 33-46.

(2012b). Navegaciones errantes. De música, jóvenes y redes: de Facebook a Youtube y viceversa. Nueva Época, 18, 135-171.

RIVERA, J. G. (2013). Juventudes en América Latina. Una reflexión desde la experiencia de la exclusión y la cultura. Papeles de población, 75, 9-34. Recuperado de: http://www.scielo.org.mx/pdf/pp/v19n75/v19n75a2.pdf

SÁNCHEZ VIDAL, A. (2007). Manual de psicología comunitaria. Un enfoque integrado. Madrid: Ediciones Pirámide.

SimmEL, G. (1917/2002). Cuestiones fundamentales de sociología. Barcelona: Gedisa. 
VAlenzuela, J. M. (Coord). (2015). Juvenicidio. Ayotzinapa y las vidas precarias en América Latina y España. México DF: ITESO/Colegio Frontera Norte/NED Ediciones. 